Strategic Behavior and the Environment, 2014, 4: 99-130

\title{
Enabling Public Participation in Strategic Environmental Assessment: An Application of Multicriteria Analysis*
}

\author{
Marta Bottero ${ }^{1}$, Valentina Ferretti ${ }^{2}$, Giulio Mondini ${ }^{3}$, \\ and Silvia Pomarico 4 \\ ${ }^{1}$ Politecnico di Torino, Department of Regional and Urban Studies and \\ Planning, Italy; marta.bottero@polito.it \\ ${ }^{2}$ Politecnico di Torino, Department of Regional and Urban Studies and \\ Planning, Italy; valentina.ferretti@polito.it \\ ${ }^{3}$ Politecnico di Torino, Department of Regional and Urban Studies and \\ Planning, Italy; giulio.mondini@polito.it \\ ${ }^{4}$ Politecnico di Torino, Department of Regional and Urban Studies and \\ Planning, Italy; silvia.pomarico@polito.it
}

\begin{abstract}
Since the last decades Strategic Environmental Assessment (SEA) has been recognized as a very important and rapidly growing area of research and application in the domain of sustainable development. It has been generally agreed that public participation must be integrated in SEA procedure because it allows information relevant to the decisionmaking process to be included. In this sense, one of the major challenge in this area is to detect some tools which are able to better link the decision-making process and the stakeholders involved in the decision.
\end{abstract}

\footnotetext{
* The contribution is the result of the joint effort of the authors. Despite the global responsibility for the work being equally shared among the four authors, it should be noted that Marta Bottero was responsible for the research outlined in Sections "Sustainable Development, SEA and Public Participation", "Description of the Case Study" and "Presentation of the Alternatives and Construction of the Network", Valentina Ferretti
}

ISSN 1944-012X; DOI 10.1561/102.00000037

(C) 2014 M. Bottero, V. Ferretti, G. Mondini and S. Pomarico 
The paper proposes an application of a method belonging to the Multiple Criteria Decision Aiding family in order to support the preparation of a land-use plan for a small town in Northern Italy, highlighting the relationship among the performed evaluation the SEA procedure and the participatory planning process that has been carried out in order to involve the population in planning decisions.

Keywords: $\quad$ Multiple Criteria Decision Aiding; urban planning; Strategic Environmental Assessment; public participation; Analytic Network Process; environmental decision-making.

\section{Introduction}

Problems related to urban planning and environmental decision-making are intrinsically complex because they involve multiple attributes which are defined by subjective evaluations (Marttunen and Hämäläinen, 1995). The actual trend seems to recognize the multidimensionality of such decision problems, considering the procedures of Environmental Impact Assessment (EIA) and Strategic Environmental Assessment (SEA).

Particularly, since the last decades Strategic Environmental Assessment (SEA) has been recognized as a very important and rapidly growing area of research and application in the domain of sustainable development (Therivel and Partidario, 1996). It has been generally agreed that public participation must be integrated in SEA processes because it allows information relevant to the decision-making process to be included and it increases the credibility of the selected programmes, plans, and policies. In this sense, one of the major challenge in this area is to detect some tools which are able to clarify the opinions of different actors and to better link the decision-making process and the stakeholders involved in the decision.

The present paper proposes an application of a method belonging to the Multiple Criteria Decision Aiding (MCDA) family in order to support the

undertook the research described in Sections "MCDA: A General Overview in the Sustainability Assessment Domain", "Calculation of Alternatives Priorities" and "Sensitivity Analysis", Giulio Mondini was responsible for the Introduction while Silvia Pomarico undertook the research described in Sections "Presentation of the Alternatives and Construction of the Network" and "Determination of Clusters and Elements Weights". The Abstract and "Discussion and Conclusions" are the result of the joint work of all the authors. 
preparation of a land-use plan for a small town in Northern Italy. The performed evaluation has been part of the SEA process of the plan and was closely integrated with the participatory planning process that has been carried out in order to involve the population in planning decisions.

MCDA methods are used to make a comparative assessment of alternative projects or heterogeneous measures (Roy and Bouyssou, 1995; Figueira et al., 2005). These methods allow several criteria to be taken into account simultaneously in a complex situation and they are designed to help Decision Makers (DMs) to integrate the different options, which reflect the opinions of the involved actors, in a prospective or retrospective framework. Participation of the DMs in the process is a central part of the approach.

Deliberative approaches that enhance public participation and collective learning processes among different actors, with different perspectives and objectives, are central in the creation of new responses to threats for environmental systems. According to this vision, many applications exist in the literature that combine deliberative approaches and MCDA to support decision-making processes (Stagl, 2006; Garmendia and Stagl, 2010).

In particular, the work refers to the application of the Analytic Network Process (ANP) technique. This technique has been developed by Saaty (Saaty, 2005; Saaty and Vargas, 2006) as the generalization of the more well-known Analytic Hierarchy Process (AHP) (Saaty, 1980, 2000) to dependences and it is particularly suitable for dealing with complex decision problems which are characterized by inter-relationships and feedbacks among the elements at stake.

The objective of the paper is to present an innovative multicriteria assessment of a land-use plan to evaluate its sustainability, focusing on how the evaluation was accomplished by a participated approach.

Therefore, the central questions discussed in the paper are as follows:

(1) Can the MCDA evaluation be integrated in the SEA process for a landuse plan?

(2) Can the MCDA evaluation be a tool for structuring deliberative and participated processes?

(3) Can the MCDA approach be a link for connecting science and policy making (Tsoukias, 2011a)?

After the Introduction section, the paper is organized as follows: the following section illustrates the general domain of application, considering sustainable development, SEA and public participation; the next section 
offers an overview of the MCDA methods, focusing in particular on the ANP technique; the application of the ANP-based model to the study case follows next; finally, the last section discusses the main findings of the application and summarises the conclusions that can be drawn from the work done.

\section{Sustainable Development, SEA and Public Participation}

Assessing territorial transformation scenarios is normally addressed through the sustainable development paradigm. Sustainable development has been defined by the Brundtland Commission (Brundtland, 1987) as the "development that meets the needs of the present without compromising the ability of future generations to meet their own needs". As argued by Pope et al. (2004), the theory of sustainability assessment as currently expressed in the literature has largely evolved from work undertaken by practitioners of Environmental Impact Assessment (EIA), and more recently Strategic Environmental Assessment (SEA), which in turn has been influenced by policy analysis techniques (Sheate et al., 2001; Partidario and Coutinho, 2011).

Particularly, SEA is a policy instrument which has been developed since the 1980s as a means to influence strategic decision-making in policies, plans or programmes of public bodies or responsible authorities (Partidario, 1999). More formally, SEA can be defined as a systematic, proactive and participative process that aims at ensuring that environmental aspects are given due consideration in planning and decision-making above the project level, frequently referred to as strategic action or policies, plans and programmes (PPPs) (European Commission, 2005).

The principal aims of the SEA process can be summarized as follows: (i) to help DMs to integrate environmental and sustainability considerations into strategic actions; (ii) to enhance environmental protection; (iii) to promote public participation in the decision-making process; (iv) to increase government and local authority transparency (Nilsson and Dalkman, 2001; Therivel, 2004).

The SEA procedure is defined by the European Directive 42/2001 and is articulated in subsequent phases (European Commission, 2005) including: Screening (Is SEA necessary for the PPP under investigation?), Scoping (What are the environmental objectives of PPP? Which issues should be discussed in the assessment? Which assessment method is feasible with 
the available data?), Environmental Assessment (How significant are the impacts? How can these be reduced if necessary? How should these be monitored after decision-making?), Review (Is the report user-friendly and unbiased? Are all the relevant issues, including alternatives, discussed? Are the forecasts and the associated methods presented clearly?), Implementation and Monitoring (Is it clear how the transport infrastructure plan is to be implemented? Are proposals for monitoring set down clearly? Is there a mechanism for correcting any unacceptable aspects of implementation?), Consultation and Participation (Is there any plan for public participation? Is there a procedure to interact with the authorities of another country in case of transboundary corridor?), Decision (Is the SEA integrated into the planning process? Is the SEA linked with other types of assessment? Is the SEA fully considered in decision-making?). Figure 1 gives a schematic

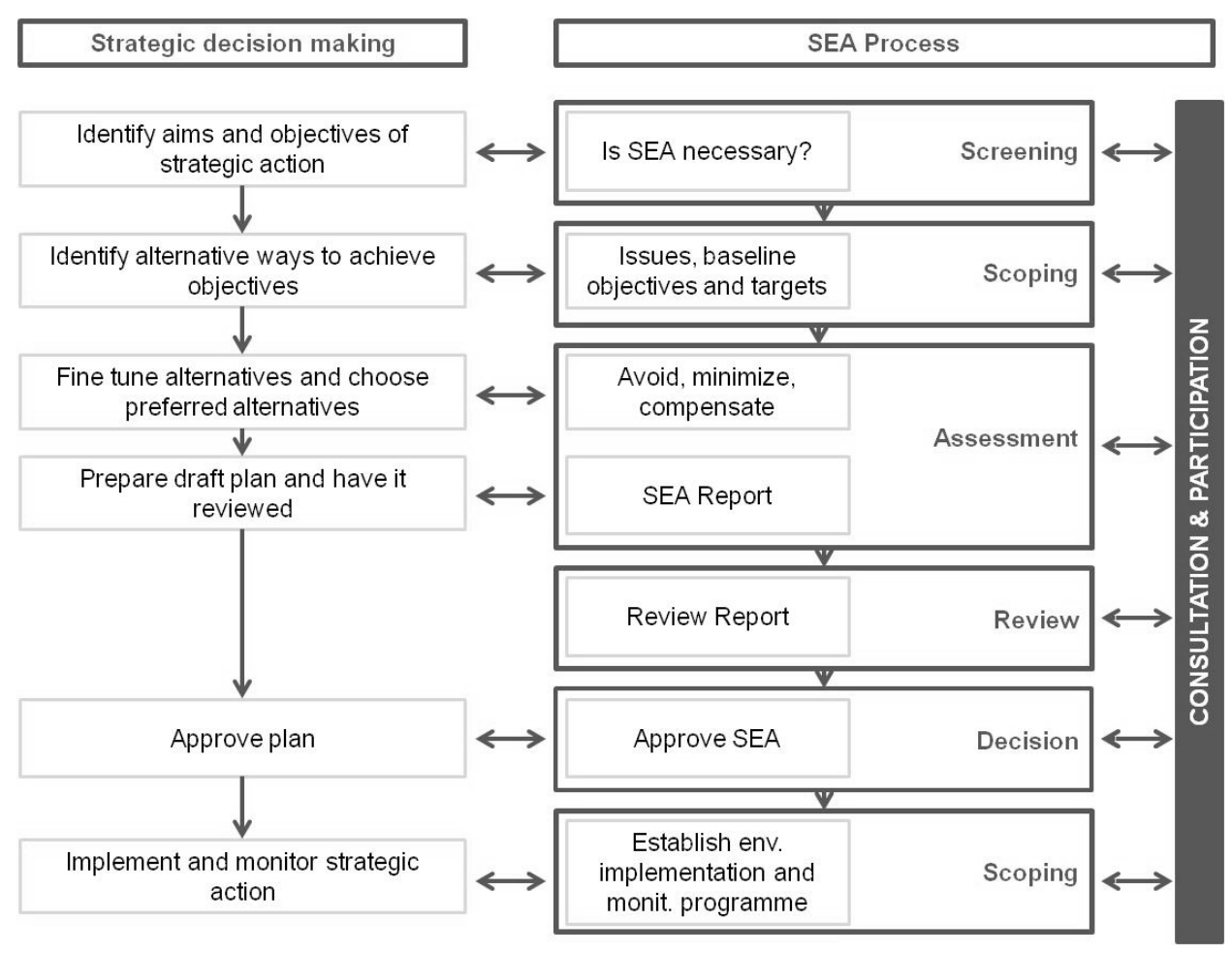

Figure 1. Representation of the overall SEA process.

(Source: Elaboration from European Commission, 2005). 
representation of the overall SEA process, highlighting the participatory and integrative approach advocated by the procedure.

SEA, as a planning approach, is designed to be a process fostering sustainable development and wellness of individuals and communities (Gauthier et al., 2011). Following this reasoning, in the domain of urban and territorial planning, SEA can be seen as a decision-making supporting tool helping communities to make meaningful choices in light of predetermined objectives. In this emerging model, which is focused on communication and cooperation of all stakeholders, public participation takes place continuously during the planning process in order to facilitate sustainable development. In anticipation of this emergence, the environmental assessment process can be seen as a prime tool for local communities to take ownership of their own development and to manage their future (Taylor et al., 1995; Vincente and Partidario, 2006; Gauthier et al., 2011).

\section{MCDA: A General Overview in the Sustainability Assessment Domain}

Multiple Criteria Decision Aiding (Roy and Bouyssou, 1995; Figueira et al., $2005)$ is a valuable and increasingly widely-used tool to aid decision-making where there is a choice to be made between competing options. It is particularly useful as a tool for sustainability assessment and urban and territorial planning, where a complex and inter-connected range of environmental, social and economic issues must be taken into consideration and where objectives are often competing, making trade-offs unavoidable.

MCDA gives not only a toolbox, but also, overall, a well developed methodology to support decision-making processes.

Moreover, MCDA has demonstrated its usefulness as a tool for conflict management and the main point of force is the fact that the use of various evaluation criteria has a direct translation in terms of plurality of values used in the evaluation process. From this point of view, MCDA can be considered as a tool for implementing political democracy (Munda, 2005).

MCDA thus provides a robust and transparent decision-making structure, making explicit key considerations and values, and providing opportunities for stakeholder and community participation.

Starting from these premises, MCDA can be applied at all levels of decision-making, from the consideration of project alternatives to broadreaching policy decisions, thus extending upwards from Environmental Impact Assessment and downwards from policy analysis. 
From the methodological point of view, multicriteria problems are commonly categorized as continuous or discrete, depending on the domain of alternatives (Zanakis et al., 1998). Hwang and Yoon (1981) classify them as (i) Multiple Attribute Decision Making (MADM) and (ii) Multiple Objective Decision Making (MODM). According to Zanakis et al. (1998), the former deals with discrete, usually limited, number of pre-specified alternatives. The latter deals with variable decision values to be determined in a continuous or integer domain of infinite or large number of choices.

In the more general domain of decision-making aiding, a very recent classification of methods has been proposed by Tsoukias (2011) considering (i) the comparison among the alternatives (preferences or similarities); (ii) the elaboration of preferential statements; (iii) the possibility of considering negative preferential statements: according to the author, the three above-mentioned classes cover the whole area of methods.

There are thus numerous approaches that all fall under the umbrella of MCDA, each involving different protocols for eliciting inputs, structures to represent them, algorithms to combine them, and processes to interpret and use formal results in actual advising or decision-making contexts (Huang et al., 2011).

Among these approaches, a very important role is played by the Analytic Network Process (ANP, Saaty, 2005; Saaty and Vargas, 2006). This technique, which represents the generalization of the more well-known Analytic Hierarchy Process (AHP, Saaty, 1980) to dependences is particularly suitable for dealing with complex decision-making processes which are characterized by inter-relationships and feedbacks among the elements at stake.

The ANP represents a theory of relative measurement on absolute scales of both tangible and intangible criteria based on both the judgement of experts and on existing measurements and statistics needed to make a decision. By freeing us from the burden of ordering the components in the form of a directed chain as in the AHP hierarchy, the ANP represents any decision as a network and allows the structure to develop more naturally. The ANP represents, therefore, a better way to describe faithfully what can happen in the real world and is gaining merit as a useful tool to help technicians make their decision processes traceable and reliable. By including dependences and feedbacks and by cycling their influence by means of the supermatrix approach, the ANP is more likely to capture what happens in the real world, thus providing effective support for the kind of decisions needed to cope with the future (Zoffer et al., 2008). 
The reasons for using an ANP-based decision approach in the present analysis are: (i) the development of a new land-use plan for a town is a multicriteria problem; (ii) there are dependencies among groups of criteria which need to be analyzed, and (iii) the detailed analysis of the interrelationships between criteria forces the Decision Makers (DMs) to carefully reflect on their project priority approach and on the decision-making problem itself. This helps DMs to gain a better understanding of the problem and to make a more reliable final decision.

From the methodological point of view, the ANP requires a network structure to represent the problem, as well as pairwise comparisons to establish the relationships within the structure.

In order to develop an ANP model, it is necessary to carry out five fundamental steps.

The first step consists in developing the structure of the decision-making process. This involves defining its main objective and identifying groups (clusters) constituted by various elements (nodes) that influence the decision, and alternatives or options from which to choose. After having chosen which structure is more suitable in the decisional context, whether the simple or the complex one (in the latter case the most common model is the so-called Benefits-Opportunities-Costs-Risks - BOCR model) (Saaty, 2005), the relationships between the different elements of the network must be identified. All the elements in the network can be related in different ways since the network can incorporate feedbacks and complex inter-relationships within and between clusters, thus providing a more accurate modeling of complex settings.

The second step consists of pairwise comparisons, in order to establish the relative importance of the different elements, with respect to a certain component of the network. Comparative or relative judgments are made on pairs of elements to ensure accuracy. In paired comparisons, the smaller element is used as the unit, and the larger element becomes a multiple of that unit with respect to the common property or criterion for which the comparisons are made. It is important to highlight that there are two levels of pairwise comparisons in the ANP: the cluster level, which is more strategic, and the node level, which is more specialized. In pairwise comparisons, a ratio scale of 1-9, that is Saaty's fundamental scale, is used to compare any two elements. The main eigenvector of each pairwise comparison matrix represents the synthesis of the numerical judgments established at each level of the network (Saaty, 1980). 
The third step consists of the progressive formation of three supermatrices: the initial or unweighted one, the weighted one and, finally, the limit one. The unweighted supermatrix contains all the eigenvectors that are derived from the pairwise comparison matrices of the model at the nodes' level. The eigenvector obtained from the cluster-level comparison, with respect to the control criterion, is applied to the initial supermatrix as a cluster weight and the result is the weighted supermatrix. The supermatrix elements allow a resolution to be made of the interdependencies that exist between the elements of the system.

The fourth step concerns the elicitation of the final priorities. In this step, the weighted supermatrix is raised to a limiting power, as in Equation (1), in order to converge and to obtain a long-term stable set of weights that represents the final priority vector.

$$
\lim _{k \rightarrow \infty} W^{k}
$$

In the case of the complex network structure, it is necessary to synthesize the outcome of the alternative priorities for each of the subnetworks in order to obtain their overall synthesis through the application of different aggregation formulas (Saaty and Vargas, 2006).

The fifth and last step consists in carrying out the sensitivity analysis on the final outcome of the model in order to test its robustness.

A very large and consolidated amount of literature concerning the ANP exists in different fields. In particular, very interesting studies have been carried out in the sphere of waste management (Aragonés-Beltrán et al., 2010; Bottero and Ferretti, 2011), strategic policy planning (Ulutas, 2005), environmental impact assessment of territorial transformations (Bottero et al., 2008; Bottero and Mondini, 2008; Liu and Lai, 2009), market and logistics (Liang and Li, 2008), economics and finance (Niemura and Saaty, 2004), civil engineering (Neaupane and Piantanakulchai, 2006) and transportation (Piantanakulchai, 2005; Tuzkaya and Onut, 2008).

\section{Application}

\section{Description of the Case Study}

The work proposes the use of the ANP method in a decision-making process concerning the development of the land-use plan for a small town in Northern 
Italy. The evaluation work has been focused on the choice of the most important areas to which it is necessary to pay more attention in the planning process and the model has been fed with information from the participatory process that had been conducted to develop the plan.

The ANP evaluation was part of the SEA procedure, which has accompanied the formation of the land-use plan since the preliminary phases related to the definition of the strategy to be followed. In particular, through the ANP method it was possible to investigate the opinion of the different stakeholders involved in the process (Public Authority, citizens, associations, etc.) in order to allow the planners to consider the obtained information in the preparation of the plan It must be highlighted that the developed approach granted a transparent decision-making process.

In real terms, a complex participatory process has been carried out during the preparation of the plan; this process has the aim of acting both at the political level, considering the definition of strategies and objectives to be pursued with the plan, and at the spatial planning level, considering the specification of real projects and actions for the town. The participatory process consisted in several public meetings and debates and in the construction of a web site through which it was possible to share documents, materials and opinions about the planning process going on (Bottero et al., 2012; Bertini and Mondini, 2012).

In particular, in the participatory process three different groups of stakeholders (citizens and associations, Environmental Authorities, private companies and practitioners) were involved in the discussion about the plan (Figure 2).

The Municipal Authority, in the capacity of the Municipal Planning Bureau (MPB), managed the search for the needs of the stakeholders through specific activities organized according to different phases:

- Firstly, the stakeholders were involved in discussing the objectives of the plan. Starting from a list of objectives prepared by the MPB, the participants were invited to correct, cancel or integrate the list.

- Secondly, once the objectives were approved, the MPB prepared a preliminary list of actions to be implemented in order to reach the different objectives. Also in this case, the participants were asked to discuss the actions proposing integrations or modifications.

- Thirdly, the different actions were voted in order to establish those actions which are the most urgent and important for the community. 


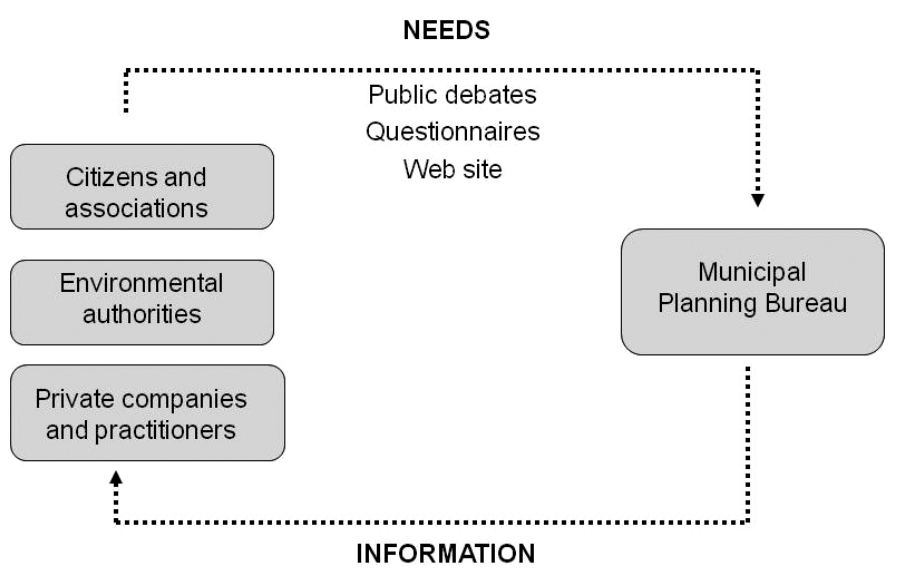

Figure 2. Structure of the procedure for developing the participatory planning process.

Around 90 people were involved in the aforementioned process and the participation was structured as follows: with reference to the first two steps, the debate was developed through specific discussion decks comprising nine participants and two specialists coming from the MPB having the role of facilitators; in relation to the third phase, the actions were voted by means of a specific questionnaire where each participant was asked to indicate the most preferred actions starting from the list discussed in the second phase. Mention has to be made to the fact that the results were presented in a plenary session.

In order to efficiently support the planning process, a decision model has been developed able to cope with the complexity of the system under analysis. From the methodological point of view, the development of the model involved the following different steps:

(i) definition of the main areas of interest for the plan based on the geographical distribution of the actions identified during the participatory process;

(ii) structuring of the decision problem in terms of objectives, subobjectives and specific actions;

(iii) weighing of all the considered factors based on both the results of the participative procedure and technical and experts judgements; 
(iv) aggregation of the results in order to obtain a priority list of the alternative options;

(v) validation of the model through a sensitivity analysis.

The different steps of the ANP model development are illustrated in the following sub-sections.

\section{Presentation of the Alternatives and Construction of the Network}

The objective of the evaluation was to identify the most important areas for the development of the small town; the planning strategies of the Municipal Plan will focus on these areas. In order to reach this objective, the territory of the town was subdivided into different portions that were compared through the evaluation process.

In this application, the identification of the alternative options and the criteria of evaluation have been directly derived from the participatory process. Particularly, as already presented in the above sub-section, the citizens were involved in the discussion on the plan and a hierarchy of objectives to be reached with the development of the plan was identified. The different objectives, either structured in general or specific objectives, were then organized into three different thematic systems, namely "urban and social system", "natural and cultural system" and "economic and mobility system", which represent the three fundamental pillars of the sustainable development approach. Moreover, the population worked together with the planning experts to identify a set of specific actions to be implemented in the town, for each of the objectives, such as the construction of a public library, the creation of new sports facilities, the amelioration of the green areas, etc.; these actions were discussed and evaluated through a questionnaire that was submitted to the population in order to find the most important actions that had to be realized in the town.

The set of actions that was identified in the participatory process was taken into account for the construction of the alternative options. The actions were examined from the point of view of their geographical distribution. The analysis of the territorial distribution of the actions led to the identification of five different areas, where the actions were concentrated, namely "hilly agricultural areas", "plain agricultural areas", "industrial areas", "suburban urban areas" and "central urban areas". Figure 3 shows the distribution of the alternatives throughout the territory while Table 1 provides a detailed description. 


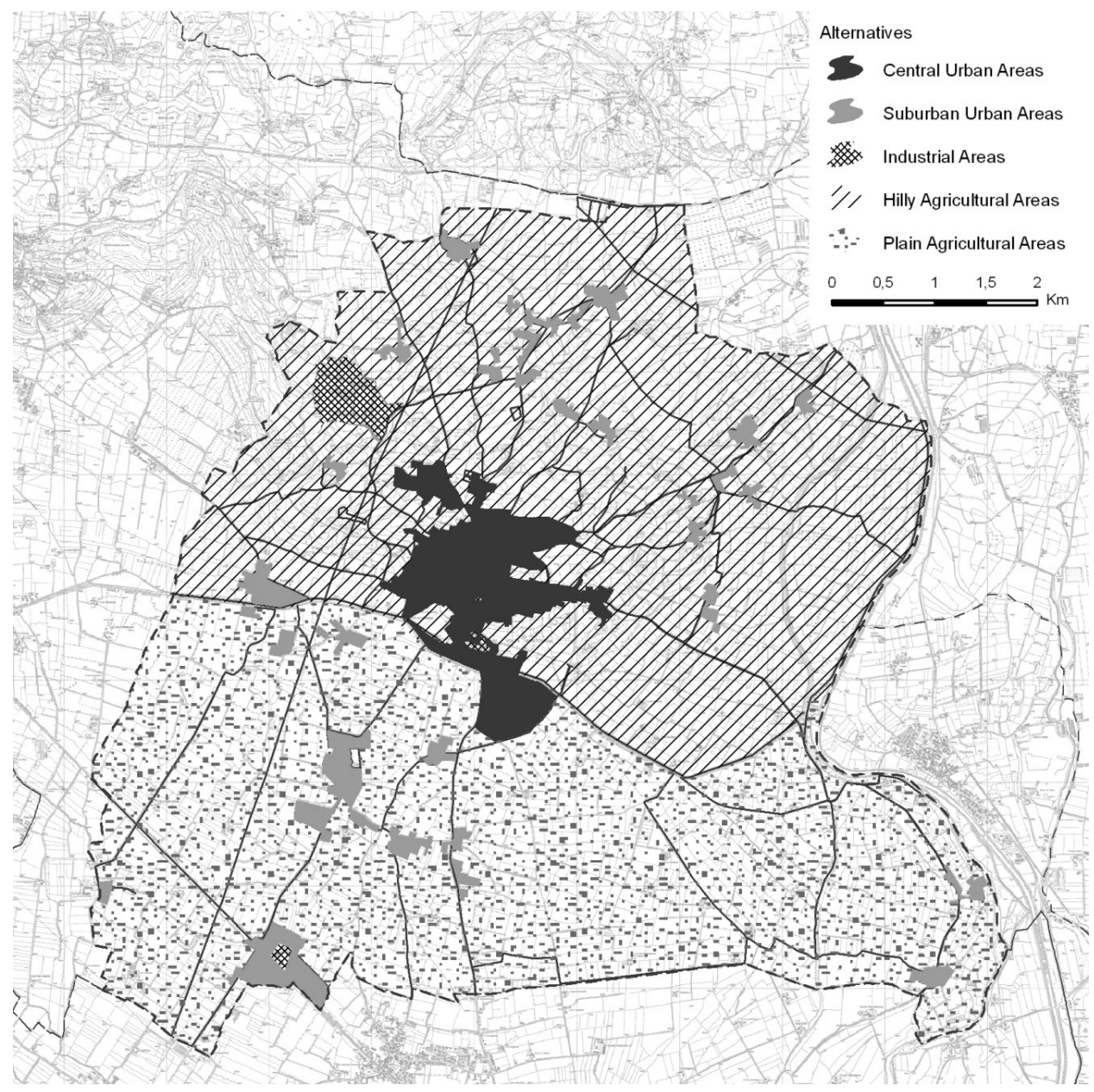

Figure 3. Map of the territory under analysis showing the five alternative areas to be ranked through the ANP model.

The aforementioned alternatives were then evaluated through the ANP approach. According to the methodology, the first step is structuring the decision problem. In this case, a complex ANP model has been used (Saaty and Ozdemir, 2008) and it was designed as follows:

- the main goal: this is related to the issue that has to be solved through the evaluation process; in this case, it refers to the identification of the 
Table 1. Description of the five alternative areas considered in the analysis.

\begin{tabular}{|c|c|}
\hline Alternatives & Description \\
\hline $\begin{array}{l}\text { Hilly } \\
\text { agricultural } \\
\text { areas }\end{array}$ & $\begin{array}{l}\text { Specific actions for the protection and the valorisation of the } \\
\text { natural vocation of the areas have been considered, with } \\
\text { particular reference to the management of the agricultural } \\
\text { landscape. Further actions are related to the enhancement of } \\
\text { the tourism sector in the areas through the amelioration of the } \\
\text { farmhouse network. }\end{array}$ \\
\hline $\begin{array}{l}\text { Plain } \\
\quad \text { agricultural } \\
\text { areas }\end{array}$ & $\begin{array}{l}\text { Punctual projects have been considered for the areas, such as } \\
\text { the creation of a new environmentally friendly industrial area } \\
\text { and the construction of a solar power plant. Particular } \\
\text { attention has been paid to the management of the existing } \\
\text { quarry activities. Moreover, as for the hilly agricultural areas, } \\
\text { specific actions have been considered for the protection and the } \\
\text { valorisation of the natural vocation of the areas and for the } \\
\text { enhancement of farmhouse tourism. }\end{array}$ \\
\hline Industrial areas & $\begin{array}{l}\text { Requalification projects are taken into account, with particular } \\
\text { reference to the abandoned industrial buildings. }\end{array}$ \\
\hline $\begin{array}{l}\text { Suburban urban } \\
\text { areas }\end{array}$ & $\begin{array}{l}\text { Different actions have been considered to improve the quality of } \\
\text { life of the inhabitants of the suburbs, with particular reference } \\
\text { to both material (road network) and immaterial (internet } \\
\text { network) communication infrastructures. }\end{array}$ \\
\hline $\begin{array}{l}\text { Central urban } \\
\text { areas }\end{array}$ & $\begin{array}{l}\text { Requalification and refunctionalisation projects have been } \\
\text { taken into account for some historical buildings in the centre of } \\
\text { the town, e.g. the library or the municipal palace. Moreover, } \\
\text { actions supporting the existing economic activities have been } \\
\text { considered. Further actions were related to the definition of } \\
\text { housing policies and to the creation of new services for the } \\
\text { population, such as green areas, schools, etc. Particular } \\
\text { importance has been given to the construction of new sport } \\
\text { facilities and to the resolution of the problems related to traffic } \\
\text { control and internal mobility. }\end{array}$ \\
\hline
\end{tabular}

most important areas to which it is necessary to pay more attention in the planning process;

- three separate subnetworks: these refer to the three systems that were identified in the participatory process, namely "urban and social 
system", "natural and cultural system" and "economic and mobility system", and they constitute the control criteria in the evaluation model;

- different clusters for each of the three subnetworks: these correspond to the general objectives of the participatory process;

- several elements for each of the clusters: these match the specific objectives of the participatory process;

- alternative options: these were determined on the basis of the actions established by the citizens and then reorganized, according to their geographical distribution, into five areas.

Figure 4 shows, in a schematic way, the structure of the ANP model that has been developed while Table 2 presents in detail the full range of elements considered in the model.

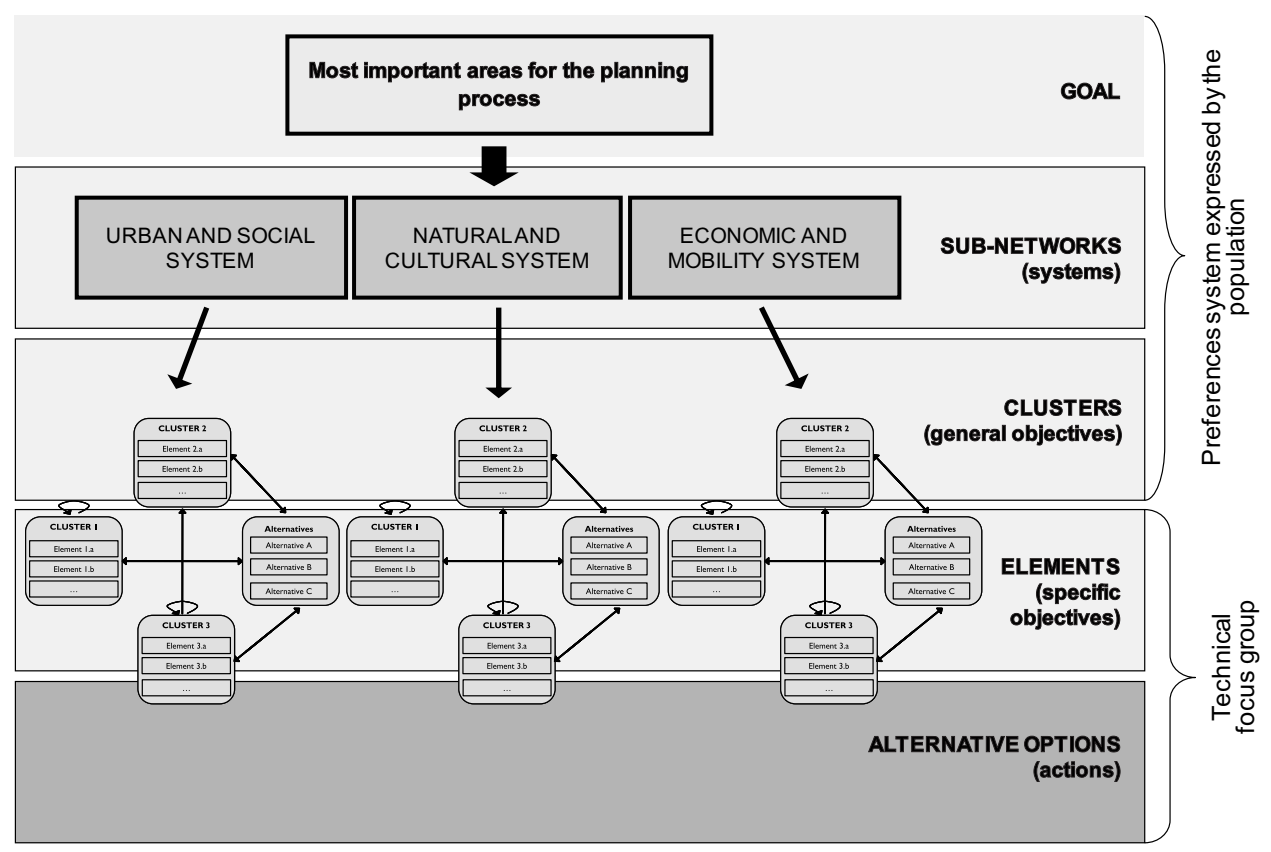

Figure 4. Structure of the ANP model used to support the decision process for the Municipal Plan. 
Table 2. Decision network of the problem.

\begin{tabular}{|c|c|c|c|}
\hline Subnetworks & Clusters & Elements & \\
\hline \multirow{12}{*}{ 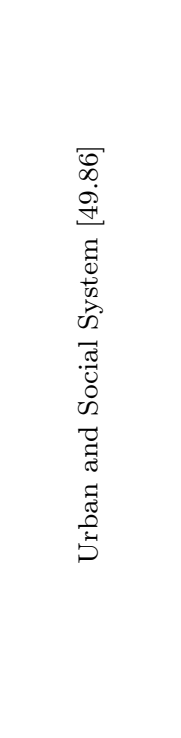 } & \multirow{8}{*}{$\begin{array}{l}\text { City valorization } \\
\text { and } \\
\text { requalification } \\
{[37.92]}\end{array}$} & $\begin{array}{l}\text { Creation of new centralities in the suburban urban } \\
\text { areas }\end{array}$ & A1 \\
\hline & & Recovery and reuse of buildings and abandoned areas & A2 \\
\hline & & $\begin{array}{l}\text { Promotion of architectural and urban projects in } \\
\text { terms of quality }\end{array}$ & A3 \\
\hline & & $\begin{array}{l}\text { Implementation of services such as areas dedicated to } \\
\text { sports, culture and meeting places }\end{array}$ & $\mathrm{A} 4$ \\
\hline & & Preservation of the original destination of the areas & A5 \\
\hline & & $\begin{array}{l}\text { Improvement of the quality of life of the poor people } \\
\text { and young couples }\end{array}$ & A6 \\
\hline & & Good quality city life for children & $\mathrm{A} 7$ \\
\hline & & Creation of an urban green areas system & A8 \\
\hline & \multirow[t]{2}{*}{$\begin{array}{l}\text { Requalification of } \\
\quad \text { downgraded } \\
\text { urban areas }[5.83]\end{array}$} & $\begin{array}{l}\text { Environmental and functional requalification of } \\
\text { downgraded urban areas, with particular reference } \\
\text { to the abandoned industrial areas }\end{array}$ & B1 \\
\hline & & $\begin{array}{l}\text { Landscape improvement and amelioration of external } \\
\text { areas and of the main gates of the town }\end{array}$ & $\mathrm{B} 2$ \\
\hline & \multirow{2}{*}{$\begin{array}{l}\text { Promotion and } \\
\text { valorization of } \\
\text { cultural events } \\
\quad[6.11]\end{array}$} & $\begin{array}{l}\text { Promotion of the community tradition of the small } \\
\text { town through the existing festivals and events in an } \\
\text { integrated way }\end{array}$ & $\mathrm{C} 1$ \\
\hline & & Pursuit of greater social involvement of the citizens & $\mathrm{C} 2$ \\
\hline \multirow{15}{*}{ 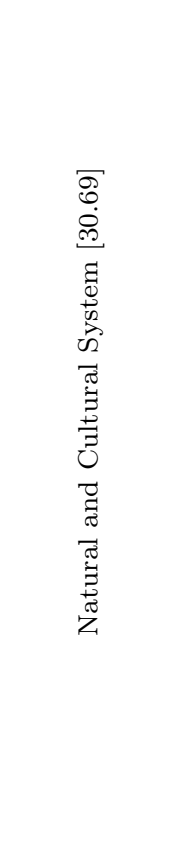 } & \multirow{8}{*}{$\begin{array}{l}\text { Optimization of } \\
\text { the use of } \\
\text { environmental } \\
\text { resources }[9.85]\end{array}$} & Reduction in energy consumption & D1 \\
\hline & & Use of renewable energy sources & D2 \\
\hline & & Reduction in waste & D3 \\
\hline & & Reduction in water consumption & D4 \\
\hline & & Efficiency in consumption of resources & D5 \\
\hline & & Exploitation of daylight & D6 \\
\hline & & Promotion of bio-architectural projects & $\mathrm{D} 7$ \\
\hline & & Optimization of the healthiness of the settlement areas & D8 \\
\hline & \multirow{4}{*}{$\begin{array}{l}\text { Protection and } \\
\text { valorization of } \\
\text { the cultural } \\
\text { heritage }[3.89]\end{array}$} & $\begin{array}{l}\text { Enhancement of agricultural areas as places of } \\
\text { multifunctionality and landscape conservation }\end{array}$ & E1 \\
\hline & & $\begin{array}{l}\text { Valorization and protection of suburban urban areas } \\
\text { as part of historical and cultural importance } \\
\text { ensuring the presence of minimum services }\end{array}$ & E2 \\
\hline & & Valorization and protection of Cultural Heritage & E3 \\
\hline & & Creation of a green belt around the town & F1 \\
\hline & \multirow{2}{*}{$\begin{array}{c}\text { Conservation } \\
\text { and } \\
\text { valorization of } \\
\text { the natural } \\
\text { heritage }[6.25]\end{array}$} & $\begin{array}{l}\text { Development of a project aimed at the reconstruction } \\
\text { of ecological corridors and at the protection of } \\
\text { existing habitats }\end{array}$ & $\mathrm{F} 2$ \\
\hline & & Increase in the use of natural-physical heritage & F3 \\
\hline & $\begin{array}{l}\text { Soil } \\
\text { consumption } \\
\text { reduction } \\
{[10.97]}\end{array}$ & Encouragement of building recovery and renovation & G1 \\
\hline
\end{tabular}


Table 2. (Continued)

\begin{tabular}{|c|c|c|c|}
\hline Subnetworks & \multirow{2}{*}{$\begin{array}{l}\text { Clusters } \\
\text { Rationalization } \\
\text { of the transport }\end{array}$} & \multicolumn{2}{|l|}{ Elements } \\
\hline & & $\begin{array}{l}\text { Rationalization of the transport system within the } \\
\text { municipality }\end{array}$ & $\mathrm{H} 1$ \\
\hline & system inside & Enlargement of the links outside the municipal area & $\mathrm{H} 2$ \\
\hline$\stackrel{\sim}{\stackrel{\circ}{\Xi}}$ & $\begin{array}{l}\text { the town } \\
\text { territory }[13.47]\end{array}$ & $\begin{array}{l}\text { Containment of urban traffic by promoting alternative } \\
\text { modes to private cars }\end{array}$ & H3 \\
\hline 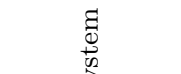 & & $\begin{array}{l}\text { Creation of a mobility system taking into account } \\
\text { citizens with mobility difficulties }\end{array}$ & $\mathrm{H} 4$ \\
\hline 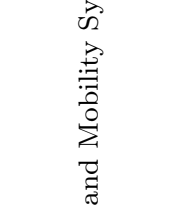 & $\begin{array}{c}\text { Promotion of } \\
\text { economic } \\
\text { activities } \\
\text { connected to the } \\
\text { tourist sector } \\
{[2.50]}\end{array}$ & Enhancement of tourist sector & I1 \\
\hline.$\circlearrowright$ & Enhancement & Diffusion of sustainable agricultural activities & L1 \\
\hline $\begin{array}{l}\text { है } \\
0 \\
0 \\
0 \\
\text { I }\end{array}$ & $\begin{array}{c}\text { of agricultural } \\
\text { areas as } \\
\text { sustainable } \\
\text { productive areas } \\
{[3.75]}\end{array}$ & $\begin{array}{l}\text { Production of a short chain with a direct relationship } \\
\text { between the producer and the citizen }\end{array}$ & $\mathrm{L} 2$ \\
\hline
\end{tabular}

The network structure of the problem and the interdependences between the clusters were simulated using the Super Decisions software, ${ }^{1}$ which automatically generates a list of the pairwise comparisons needed to run the evaluation. This software implements all the steps of the model development according to the ANP methodology.

\section{Determination of Clusters and Elements Weights}

Once the network has been identified and all the relationships between the elements have been established, it is necessary to develop the comparison and evaluation phase.

With reference to the ANP methodology, this step of the analysis consists of pairwise comparisons, in order to establish the relative importance of the different elements, with respect to a certain component of the network. In the case under examination, two separate strategies have been used to approach this task, according to the level of the evaluation:

- with reference to the weighting of control criteria and clusters of the analysis, the values were directly derived from the preferences system,

1 www.superdecisions.com 
expressed by the population for the actions during the participatory process for the discussion of the plan ${ }^{2}$;

- with reference to the weighting of elements and alternative options, the values were derived by a specific focus group where different actors worked together to fill in the pairwise comparison matrices.

This approach allows the preferences of the citizens to be inserted in the model and the experts' opinions concerning the technical performances of the alternative to be considered.

The weights obtained at the control criteria and clusters levels are showed in Table 2.

With reference to the elements and alternatives level, the evaluation has been carried out through pairwise comparisons, according to the influence and interdependence relationships established in the network.

Since the criteria weighting is a largely subjective step of the decisionmaking process, a focus group has been organized where several experts have been involved in order to discuss and evaluate the alternative performance with respect to the model elements. With the aim of making up a multidisciplinary group able to tackle the complexity of the problem, the focus group brought together experts in the field of spatial planning, environmental assessment, sustainability assessment procedures and several representatives coming from the Municipal Administration of the town. In particular, taking into account the considerable number of questions arisen from the model development, the focus group participants were divided into small groups. Each group was composed by a member of the Municipal Administration, who knows the project under analysis, and a technical expert who answered the specific questions concerning his field of expertise. In addition, these group were supported by the aid of a facilitator during the evaluation

2 The procedure used in order to take into account the preference system expressed by the population was organized as follows: firstly, the sum of all preferences expressed for the actions was calculated and divided by 10 (citizens, when expressing their preferences for the actions, had to indicate 10 preferred actions out of the whole set); secondly, the figures thus obtained were normalized using each of the three systems and expressed in percentage terms; thirdly, the values of the actions related to the same specific objective were summed; fourthly, the figures related to each specific objective obtained in the previous step were further summed with respect to the related general objective: these sums represent the weights of the clusters in the ANP model; finally, by summing the values that were calculated for the general objective, it was possible to obtain the weights of the three subnetworks with respect to the main goal of the model. 
process. The numerical judgments established during the focus group were used to fill the pairwise comparison matrices.

For example, a question that had to be solved by the focus group was of the type:

With references to the evaluation of the most important areas for the planning process of the Municipal Plan, which alternative offers the best possibility of achieving the objective of pursuing the greater social involvement of citizens? And to what extent?

\begin{tabular}{|c|c|c|c|c|c|c|c|c|c|c|c|c|c|c|c|c|c|}
\hline Hilly & 9 & 8 & & 6 & 5 & 4 & 3 & 2 & 1 & 2 & 3 & 7 & 5 & 6 & 7 & 8 & 9 \\
\hline Hilly & & 8 & & 6 & & & & & & & & & & 6 & 7 & 8 & 9 \\
\hline Hilly & 9 & $\varepsilon$ & & & & & & & & & & & 5 & & 7 & & 9 \\
\hline Hilly & 9 & 8 & & 6 & & & & & & & 3 & & 5 & 6 & 7 & 8 & 9 \\
\hline lain agricultural areas & 3 & 0 & & 6 & & 4 & & 2 & & & 3 & & 5 & 6 & 7 & 8 & 9 \\
\hline lain agri & 8 & 8 & & 6 & 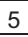 & 4 & & 2 & & 2 & 5 & & 0 & & 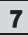 & & 9 \\
\hline eas & 0 & 8 & & 6 & & & & 2 & & & & & & & 7 & & 9 \\
\hline Indus & & 8 & & 6 & & & & & & & & & & & 7 & & 9 \\
\hline & 0 & 8 & 7 & 6 & 5 & 4 & 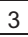 & 2 & - & - & 3 & 7 & 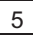 & 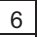 & $r$ & 0 & 9 \\
\hline uburban urban areas & 0 & 8 & 7 & 6 & & 4 & 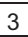 & 2 & 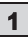 & 2 & 3 & 4 & 5 & 6 & 7 & 8 & 0 \\
\hline
\end{tabular}

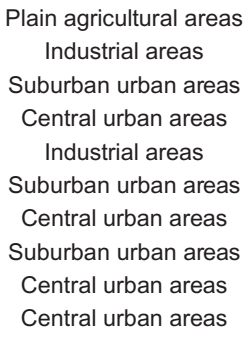

The expressed judgments were used to fill in the related comparison matrix (Table 3). The table shows the pairwise comparison matrix and the main

Table 3. Pairwise comparison matrix of the alternatives with reference to the objective of pursuing the greater social involvement of citizens.

\begin{tabular}{lcccccc}
\hline $\begin{array}{l}\text { Pursuing } \\
\text { greater social } \\
\text { involvement } \\
\text { of the citizens }\end{array}$ & $\begin{array}{c}\text { Hilly } \\
\text { agricul- } \\
\text { tural } \\
\text { areas }\end{array}$ & $\begin{array}{c}\text { Plain } \\
\text { agricul- } \\
\text { tural } \\
\text { areas }\end{array}$ & $\begin{array}{c}\text { Industrial } \\
\text { areas }\end{array}$ & $\begin{array}{c}\text { Suburban } \\
\text { urban } \\
\text { areas }\end{array}$ & $\begin{array}{c}\text { Central } \\
\text { urban } \\
\text { areas }\end{array}$ & Priority \\
\hline $\begin{array}{c}\text { Hilly } \quad \\
\quad \text { agricultural }\end{array}$ & 1 & 1 & $1 / 7$ & $1 / 7$ & $1 / 7$ & $\mathbf{0 . 0 4 1}$ \\
$\quad \begin{array}{l}\text { areas } \\
\begin{array}{c}\text { Plain } \\
\text { agricultural }\end{array}\end{array}$ & 1 & 1 & $1 / 7$ & $1 / 7$ & $1 / 7$ & $\mathbf{0 . 0 4 1}$ \\
$\quad \begin{array}{l}\text { areas } \\
\begin{array}{l}\text { Industrial } \\
\text { areas }\end{array}\end{array}$ & 7 & 7 & 1 & $1 / 3$ & $1 / 3$ & $\mathbf{0 . 1 9 4}$ \\
$\begin{array}{c}\text { Suburban } \\
\text { urban areas }\end{array}$ & 7 & 7 & 3 & 1 & 1 & $\mathbf{0 . 3 6 2}$ \\
$\begin{array}{c}\text { Central urban } \\
\text { areas }\end{array}$ & 7 & 7 & 3 & 1 & 1 & $\mathbf{0 . 3 6 2}$ \\
\hline
\end{tabular}


eingenvector which represents the priorities of the alternatives with respect to the objective of pursuing the greater social involvement of citizens.

The local priorities of the elements thus obtained form the so-called initial supermatrix. In order to provide a clear explanation of the model development, Annex I reports the unweighted and the weighted supermatrices for each subnetwork.

\section{Calculation of the Alternatives Priorities}

Each column of the limit supermatrices obtained from the three subnetworks provides the final priority vector of all the elements being considered (Table 4). For the expansions of abbreviations in Table 4 please refer to Table 2.

Leaving aside the priorities of the alternatives, the results of the complex ANP model highlight that the most important elements in the identification of the strategic areas for the development of the small town are the following:

- "environmental and functional requalification of downgraded urban areas, with particular reference to the abandoned industrial areas" in the "urban and social system" (0.100);

- "encouragement of building recovery and renovation" in the "natural and cultural system" (0.173);

- "rationalization of the transport system within the municipality" in the "economic and mobility system" (0.112).

Finally, in order to obtain the ranking of the different areas in the analysis, it was necessary to synthesize the raw priorities of the alternatives derived from the limit supermatrices by normalizing them by cluster. The values thus obtained were then combined using an appropriate aggregative formula (Saaty, 2005; Saaty and Ozdemir, 2008; Wijnmalen, 2007). The present application made use of an additive-type formula based on the weighted sum of the priorities obtained in each subnetwork according to the merits of the three control systems being considered, as illustrated in Equation (2).

$$
\operatorname{ptot}_{i}=\mathrm{SU}^{*} \mathrm{pu}_{i}+\mathrm{SN}^{*} \mathrm{pn}_{i}+\mathrm{SE}^{*} \mathrm{pe}_{i}
$$

where ${ }^{*}$ ptot $_{i}$ represents the overall score obtained from alternative $i$; SU, SN and SE represent the weights of the urban and social system, the natural and cultural system and the economic and mobility system, respectively; $\mathrm{pu}_{i}, \mathrm{pn}_{i}$ and $\mathrm{pe}_{i}$ represent the scores obtained from alternative $i$ in the urban and 
Table 4. Limit priorities for the elements of the model.

\begin{tabular}{|c|c|c|c|}
\hline Control Criteria & Clusters & Nodes & Priorities \\
\hline \multirow{17}{*}{ 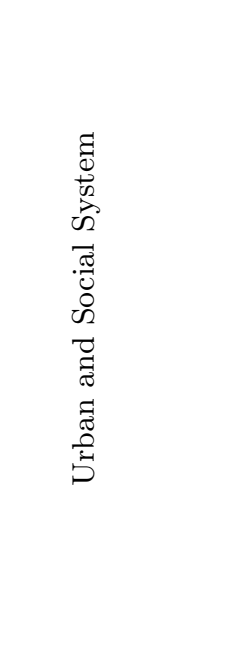 } & \multirow[t]{5}{*}{ Alternatives } & Alt 1 & 0.035 \\
\hline & & Alt 2 & 0.033 \\
\hline & & Alt 3 & 0.167 \\
\hline & & Alt 4 & 0.132 \\
\hline & & Alt 5 & 0.087 \\
\hline & \multirow[t]{8}{*}{ City valorization and requalification } & $\mathrm{A} 1$ & 0.041 \\
\hline & & $\mathrm{A} 2$ & 0.074 \\
\hline & & A3 & 0.080 \\
\hline & & A4 & 0.054 \\
\hline & & A5 & 0.016 \\
\hline & & A6 & 0.019 \\
\hline & & A7 & 0.025 \\
\hline & & A8 & 0.038 \\
\hline & \multirow[t]{2}{*}{ Requalification of downgraded urban areas } & B1 & 0.100 \\
\hline & & $\mathrm{B} 2$ & 0.030 \\
\hline & \multirow[t]{2}{*}{ Promotion and valorization of cultural events } & $\mathrm{C} 1$ & 0.033 \\
\hline & & $\mathrm{C} 2$ & 0.036 \\
\hline \multirow{20}{*}{ 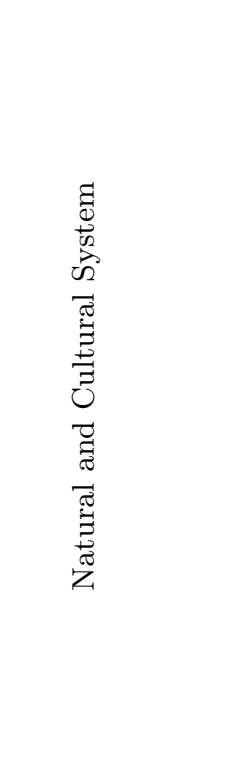 } & \multirow[t]{5}{*}{ Alternatives } & Alt 1 & 0.107 \\
\hline & & Alt 2 & 0.083 \\
\hline & & Alt 3 & 0.136 \\
\hline & & Alt 4 & 0.082 \\
\hline & & Alt 5 & 0.082 \\
\hline & \multirow[t]{8}{*}{ Optimization of the use of environmental resources } & D1 & 0.015 \\
\hline & & D2 & 0.013 \\
\hline & & D3 & 0.008 \\
\hline & & D4 & 0.012 \\
\hline & & D5 & 0.036 \\
\hline & & D6 & 0.016 \\
\hline & & D7 & 0.019 \\
\hline & & D8 & 0.062 \\
\hline & \multirow[t]{3}{*}{ Protection and valorization of the cultural heritage } & E1 & 0.025 \\
\hline & & $\mathrm{E} 2$ & 0.028 \\
\hline & & E3 & 0.012 \\
\hline & \multirow[t]{3}{*}{ Conservation and valorization of the natural heritage } & F1 & 0.024 \\
\hline & & $\mathrm{F} 2$ & 0.035 \\
\hline & & F3 & 0.034 \\
\hline & Soil consumption reduction & G1 & 0.173 \\
\hline
\end{tabular}


Table 4. (Continued)

\begin{tabular}{|c|c|c|c|}
\hline Control Criteria & Clusters & Nodes & Priorities \\
\hline \multirow{12}{*}{ 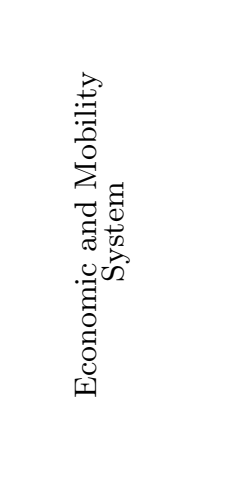 } & \multirow[t]{5}{*}{ Alternatives } & Alt 1 & 0.077 \\
\hline & & Alt 2 & 0.059 \\
\hline & & Alt 3 & 0.016 \\
\hline & & Alt 4 & 0.139 \\
\hline & & Alt 5 & 0.196 \\
\hline & \multirow{4}{*}{$\begin{array}{l}\text { Rationalization of the transport system inside } \\
\text { the town territory }\end{array}$} & H1 & 0.112 \\
\hline & & $\mathrm{H} 2$ & 0.071 \\
\hline & & H3 & 0.089 \\
\hline & & $\mathrm{H} 4$ & 0.085 \\
\hline & $\begin{array}{l}\text { Promotion of economic activities connected to } \\
\text { the turist sector }\end{array}$ & I1 & 0.087 \\
\hline & \multirow{2}{*}{$\begin{array}{l}\text { Enhancement of agricultural areas as sustainable } \\
\text { productive areas }\end{array}$} & L1 & 0.030 \\
\hline & & L2 & 0.037 \\
\hline
\end{tabular}

social system subnetwork, in the natural and cultural system subnetwork and in the economic and mobility system subnetwork, respectively.

The application of formula (2) to the results obtained in the model provides the final ranking of the alternatives under analysis. According to the calculations made the most important area for the development of the small town is that of the "industrial areas" (0.289), followed by the "suburban urban areas" (0.245), by the "central urban areas" (0.211), by the "hilly agricultural areas" (0.140) and finally by the "plain agricultural areas" (0.115).

\section{Sensitivity Analysis}

After obtaining a ranking of the alternatives it is useful to perform a sensitivity analysis on the final outcome of the model in order to test its robustness. The sensitivity analysis is concerned with a "what-if" kind of question to see if the final answer is stable when the inputs, whether judgments or priorities, are changed. It is of special interest to see whether these changes modify the order of the alternatives.

Having used an additive formulation, it is possible to measure the sensitivity of the alternatives to the control criteria weights, since the meaningful changes could not be obtained by a multiplicative formulation (Tuzkaya et al., 2007). The sensitivity analysis for the three sub-networks 
is represented in Figure 5, where the $x$ axis represents the changes in the weight of the control criteria while the $y$ axis represents the changes in the weights of the alternatives.

When the relationships between the economic and mobility system and the alternatives (Figure 5a) are considered, it is possible to notice that some alternatives (the suburbs urban areas, the hills agricultural areas and the plain agricultural areas) are not sensitive to the changes in the weight of

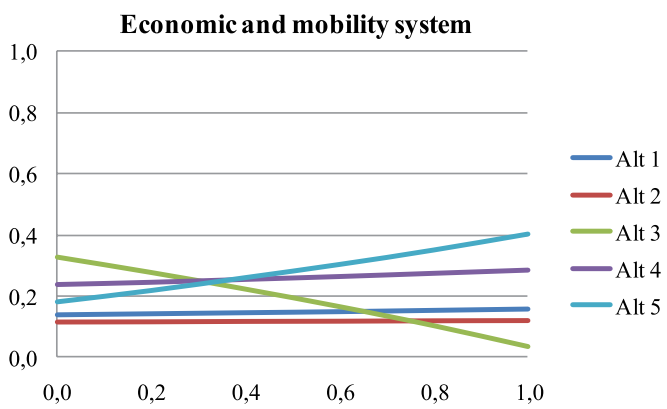

(a)

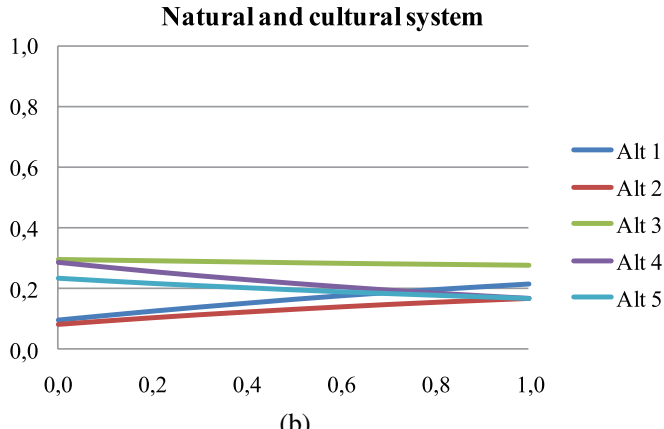

(b)

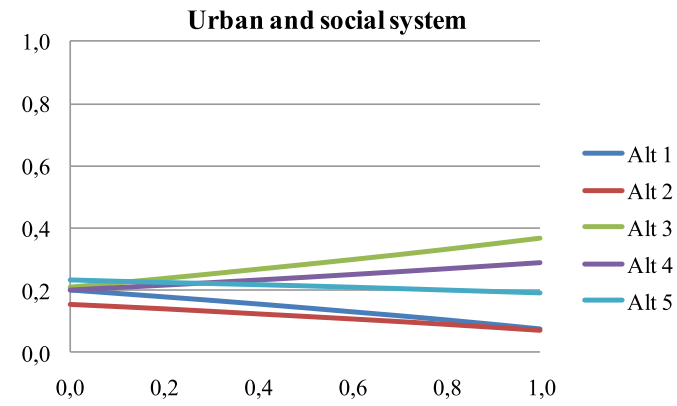

(c)

Figure 5. Sensitivity analysis for each sub-network. 
the economic and mobility system while the central urban areas and the industrial areas are sensitive, in an opposite way, to the changes in the weight of the considered control system. As a matter of fact, the share of the central urban areas increases while that of the industrial areas decreases by raising the weight of the economic and mobility system. Thus the central urban areas have positive features while the industrial areas have negative features, in terms of economic and mobility aspects.

With reference to the natural and cultural system (Figure 5b) it becomes clear that all the alternatives except for the industrial areas are sensitive to the changes in the weight of the system under analysis. The suburbs urban areas and the central urban areas have negative features in terms of natural and cultural aspects so that the increase in the weight of the system negatively affects their share; vice versa for the hills agricultural areas and for the plain agricultural areas.

Finally when the sensitivity analysis is performed on the urban and social system (Figure 5c), it is interesting to note how the situation is almost the opposite with respect to the previous sub-network. The hills agricultural areas and the plain agricultural areas have now negative features in terms of urban and social aspects so that the increase in the weight of the system negatively affects their share; vice versa for the industrial areas and the suburbs urban areas. The central urban areas are instead not sensitive to the changes in the weight of the urban and social system.

\section{Discussion and Conclusions}

The paper illustrates the application of the ANP to the decision problem concerning an urban planning process for a small town in Northern Italy. The evaluation has focused on the choice of the most important areas for the development of the Municipal Plan and the model has been fed with information coming from the participatory process that had been conducted to develop the plan. Starting from the planning goals that matter most to the citizens and the actions they would like to see implemented to enhance these goals, the municipal territory has been divided into five strategic areas for the future development of the town. The results of the performed analysis provide a priority list of the areas under examination where the "industrial areas" have the highest score.

With reference to the research question No. 1 - Can the MCDA evaluation be integrated in the SEA process for a land-use plan? - we can answer 
as follows: as reported by Huang et al. (2011), decision making in planning process requires consideration of trade-off among socio-political, economic and environmental impacts, and MCDA emerged as a formal methodology to face available technical information and stakeholders values. In the performed application, we found that the evaluation addresses the requirement coming from the SEA European legislation (Directive 42/2001) because it effectively involves bringing together social, economic and environmental concerns and the formulation of options. The proposed approach seems to constitute a real integrated decision support tool able to both generate and compare alternative options, thus aiding strategic thinking about the likely environmental, social and economic consequences of current and possible future trends and the consequences of making particular policy choices (Schetke et al., 2012).

In strict connection with the abovementioned question, we posed question No. 2 - Can the MCDA evaluation be a tool for structuring deliberative and participated processes? In this case, we found that the developed model has offered a creative way of combining decision-making support and participatory planning procedures through an integrated approach that is able to provide a systematic course of analysis of the alternatives under examination. The purpose of urban planning is to improve the living environment of a city. Therefore, public participation is very important for the success of the planning process, since any plan will ultimately become part of the everyday life of the public and only public participation allows planners and designers to access community expertise and local knowledge, thus leading to better plans and designs (Al-Kodmany, 1999; Wu et al., 2010).

The ANP method has resulted to be suitable to deal with public participation in decision problems related to urban planning for several reasons. To start with, the method allows the most important elements of the decision problem to be highlighted through a transparent and traceable decisionmaking process thus facilitating deliberation; secondly, the technique supports communication with the DMs and grants a mutual understanding.

Finally, we addressed question No. 3 - Can the MCDA approach be a link for connecting science and policy making? This is the most difficult and stimulating question for which the research is still going on (Tsoukias, 2011a). In our case, we can affirm that one of the most significant strengths of the adopted methodology is represented by the fact that the DM gains more awareness of the elements at stake while structuring the model and thus learns about the problems while solving them. Despite the complexity of 
the decision environment and the challenge for the decision support process posed by public involvement, citizen participation has also proved to enhance learning.

On the other side, the main drawback in the practical application of the ANP is a consequence of the complexity of the decision-making problem that has to be analyzed. To this end, the ANP prescribes a high number of comparisons that occasionally become too complex to understand for DMs who are not familiar with the method. Hence, a great deal of attention should be devoted to the elaboration of the questionnaires and the comparison process should be helped by a facilitator (Gomez-Navarro et al., 2009; Aragonés-Beltràn et al., 2010).

There are still a number of opportunities for expanding the study and for validating the obtained results. Firstly, considering the actual international trends on decision analysis, MCDA methods based on indirect preference information are of increasing interest because they require less cognitive effort by the DM: in this context, mention should be made of the theory of the Dominance- based Rough Sets Approach (DRSA) which offers the possibility of elicitating the DM's preferences from the analysis of exemplary decisions provided by the DM (Greco et al., 2001).

Secondly it would be of scientific interest to implement the sensitivity analysis of the model modifying the influences between the elements and the alternatives in order to see if any changes occur in the final priority list of the alternatives. In particular, the priorities of the elements of the model resulting from the limit supermatrix will be considered and, for each of the three subnetworks, the highest priority alternative and the highest priority element in each cluster will be taken into account. In order to perform the analysis, the influences among the aforementioned elements will be changed in the unweighted supermatrix. The original values will be modified by $\pm 50 \%$ in a three-step process (Aragonés-Beltràn et al., 2010), resulting in several possible combinations which will generate new rankings of alternatives.

Finally, given the spatial nature of the decisional problem under analysis, future improvements of the work will refer to the integration of the MCDA tool with Geographic Information Systems in order to develop a Multicriteria-Spatial Decision Support System (MC-SDSS) that will enable multi-purpose planning (Malczewski, 1999). In this sense, visualization techniques are of great importance to present and communicate the results to DMs and the interest groups (Wu et al., 2010). The use of computer-based 
visualization techniques could be an important contribution to the evolution of participatory planning and design, progressing towards the art of designing with people (Al-Kodmany, 1999).

In conclusion, the adopted methodology has been successful because it allowed the complex planning context to be structured and the stakeholders' perspectives to be communicated and taken into consideration. Moreover, through the performed application all the actors were aware of being involved; this enhanced the transparency of the decision process and thus increased acceptance.

\section{References}

Al-Kodmany, K. 1999. "Using Visualization Techniques for Enhancing Public Participation in Planning and Design: Process, Implementation, and Evaluation." Landscape and Urban Planning 45: 37-45.

Aragonés-Beltrán, P., J. P. Pastor-Ferrando, F. Garcìa-Garcìa, and A. Pascual-Agullò. 2010. "An Analytic Network Process Approach for Siting a Municipal Solid Waste Plant in the Metropolitan Area of Valencia (Spain)." Journal of Environmental Management 91: 1071-1086.

Bertini, A. and G. Mondini. 2012. "Progettazione partecipata e sviluppo sostenibile: l'esperienza del Piano di Governo del Territorio del Comune di Volta Mantovana." Valori e Valutazioni 8: 39-57.

Bottero, M., I. M. Lami, and P. Lombardi. 2008. Analytic Network Process. La valutazione di scenari di trasformazione urbana e territoriale Firenze, Italy: Alinea.

Bottero, M. and G. Mondini. 2008. "An Appraisal of Analytic Network Process and Its Role in Sustainability Assessment in Northern Italy." International Journal of Management of Environmental Quality 19(6): 642-660.

Bottero, M. and V. Ferretti. 2011. "An Analytic Network Process-based Approach for Location Problems: The Case of a Waste Incinerator Plant in the Province of Torino (Italy)." Journal of Multicriteria Decision Analysis 17: 63-84.

Bottero, M., L. Ingaramo, G. Mondini, and S. Sabatino. 2012. "Partecipazione pubblica e perequazione urbanistica: Lesperienza del piano di governo del territorio del comune di Volta Mantovana." In Il negoziato pubblico privato nei progetti urbani, Stanghellini, S. (ed.), Roma, Italy: DEI.

Bruntland, G. (ed.) 1987. Our Common Future, Oxford, UK: Oxford University Press.

European Commission, Directorate-General for Energy and Transport 2005. The SEA Manual. Available at http://ec.europa.eu/environment/eia/sea-studies-andreports/beacon_manuel_en.pdf [Accessed on 23 January 2012].

Figueira J., S. Greco, and M. Ehrgott, (eds.) 2005. Multiple Criteria Decision Analysis. State of the Art Survey, New York, USA: Springer.

Garmendia, E. and S. Stagl. 2010. "Public Participation for Sustainability and Social Learning: Concepts and Lessons from Three Case Studies in Europe." Ecological Economics 69: 1712-1722.

Gauthier, M., L. Simard, and J. P. Waaub. 2011. "Public Participation in Strategic Environmental Assessment (SEA): Critical Review and the Quebec (Canada) Approach." Environmental Impact Assessment Review 31: 48-60.

Gomez-Navarro, T., M. Garcia-Melon, S. Acuna-Dutra, and D. Diaz-Martin. 2009." An Environmental Pressure Index Proposal for Urban Development Planning Based on the Analytic Network Process." Environmental Impact Assessment Review 29: 319-329. 
Greco, S., B. Matarazzo, and R. Slowinski. 2001. "Rough Sets Theory for Multicriteria Decision Analysis." European Journal of Operational Research 129: 1-47.

Huang, I. B., J. Keisler, and I. Linkov. 2011. "Multi-criteria Decision Analysis in Environmental Sciences: Ten Years of Applications and Trends." Science of the Total Environment 409: 3578-3594.

Hwang, C. L. and K. Yoon. 1981. Multiple Attribute Decision Making: Methods and Applications, Berlin, Germany: Springer Verlag.

Liang, C. and Q. Li. 2008. "Enterprise Information System Project Selection with Regard to BOCR." International Journal of Project Management 26(8): 810-820.

Liu, K. F. R. and J. H. Lai. 2009. "Decision-support for Environmental Impact Assessment: A Hybrid Approach Using Fuzzy Logic and Fuzzy Analytic Network Process." Expert Systems with Applications 36(3): 5119-5136.

Malczewski, J. 1999. GIS and Multicriteria Decision Analysis, New York, USA: John Wiley and Sons.

Marttunen, M. and R. P. Hämäläinen. 1995. "Decision Analysis Interviews in Environmental Impact Assessment." European Journal of Operational Research 87: 551-563.

Munda, G. 2005. "Multiple Criteria Decision Analysis and Sustainable Development." In Multiple Criteria Decision Analysi: State of the Art Surveys, Figueira J., S. Greco, and M. Ehrgott, (eds.), New Yourk, USA: Springer.

Neaupane, K. M. and M. Piantanakulchai. 2006. "Analytic Network Process Model for Landslide Hazard Zonation." Engineering Geology 85: 281-294.

Niemura, M. P. and T. L. Saaty. 2004. "An Analytic Network Process Model for FinancialCrisis Forecasting." International Journal of Forecasting 20(4): 573-587.

Nilsson, M. and H. Dalkmann. 2001. "Decision Making and Strategic Environmental Assessment." Journal of Environmental Assessment and Policy Management 3(3): 305-327.

Partidario, M. R. 1999. "Strategic Environmental Assessment: Key Issues Emerging from Recent Practice." Environmental Impact Assessment Review 16(1): 31-55.

Partidario, M. R. and M. Coutinho. 2011. "The Lisbon New International Airport: The Story of a Decision-making Process and the Role of Strategic Environmental Assessment." Environmental Impact Assessment Review 31: 360-367.

Piantanakulchai, M. 2005. "Analytic Network Process Model for Highway Corridor Planning." Proceedings of ISAHP 2005. Honolulu, Hawaii.

Pope, J., D. Annandale, and A. Morrison-Saunder. 2004. "Conceptualizing Sustainability Assessment." Environmental Impact Assessment Review 24: 595-616.

Roy, B. and D. Bouyssou. 1995. Aide multicritère à la décision: méthodes et case, Paris, France: Economica.

Saaty, T. L. 1980. The Analytic Hierarchy Process, New York, USA: McGraw Hill.

Saaty, T. L. 2000. Fundamentals of Decision-making and Priority Theory with the Analytic Hierarchy Process, Pittsburgh, USA: RWS Publications.

Saaty, T. L. 2005. Theory and Applications of the Analytic Network Process Pittsburgh, USA: RWS Publications.

Saaty, T. L. and M. S. Ozdemir, 2008. The Encyclicon. A Dictionary of Complex Decisions Using the Analytic Network Process Pittsburgh, USA: RWS Publications.

Saaty TL. and L.G. Vargas 2006. Decision Making with the Analytic Network Process New York, USA: Springer.

Schetke, S., D. Haase, and T. Kötter. 2012. "Towards Sustainable Settlement Growth: A New Multi-criteria Assessment for Implementing Environmental Targets into Strategic Urban Planning." Environmental Impact Assessment Review 32: 195-210.

Sheate, W., S. Dagg, J. Richardson, R. Aschemann, J. Palerm, and U. Steen. 2001. SEA and Integration of the Environment into Strategic Decision-Making, Vol. 1. London, UK: Imperial College Consultants.

Stagl, S. 2006. "Multicriteria Evaluation and Public Participation: The Case of UK Energy Policy." Land Use Policy 23: 53-62. 
Taylor, C. N., C. Goodrich, and B. Hobson. 1995. "Issues-oriented Approach to Social Assessment and Project Appraisal." Project Appraisal 10(3): 142-154.

Therivel, R. 2004. Strategic Environmental Assessment in Action, London, UK: Earthscan. Therivel R. and M. R. Partidario (eds.) 1996. The Practice of Strategic Environmental Assessment, London, UK: Earthscan

Tsoukias, A. 2011a. Methods and Tools for Public Policy Evaluation, Working paper, LAMSADE-CNRS, Université Paris-Dauphine, Paris.Available at http://www. lamsade.dauphine.fr/ tsoukias/teaching.htm [Accessed on 23 January 2012].

Tsoukiàs, A. 2011b. "Aiding to Decide: Concepts and Issues." In Evaluation and Decision Models: Real Case Studies, Bisdorff, R., L. Dias, V. Mousseau, and M. Pirlot, (eds.), Berlin, Germany: Springer-Verlag.

Tuzkaya, G. and S. Onut. 2008. "A Fuzzy Analytic Network Process Based Approach to Transportation-mode Selection Between Turkey and Germany: A Case Study." Information Sciences 178(15): 3133-3146.

Tuzkaya, G., Onut, S., and Gulsun, B. 2007. An Analytic Network Process Approach for Locating Undesiderible Facilities. An Example from Istanbul, Turkey. Journal of Environmental management 88: 970-983.

Ulutas, B. H. 2005. "Determination of the Appropriate Energy Policy for Turkey." Energy 30(7): 1146-1161.

Vicente, G. and M. R. Partidario. 2006. "SEA Enhancing Communication for Better Environmental Decisions." Environmental Impact Assessment Review 26: 696-706

Wijnmalen, D. J. D. 2007. "Analysis of Benefits, Opportunities, Costs, and Risks (BOCR) with the AHP-ANP: A Critical Validation." Mathematical and Computer Modelling 46(7/8): 892-905.

Wu, H., Z. He, and J. Gong. 2010. "A Virtual Globe-based 3D Visualization and Interactive Framework for Public Participation in Urban Planning Processes." Computers, Environment and Urban Systems 34: 291-298.

Zanakis, S. H., A. Solomon N. Wishart, and S. Dublish. 1998 "Multi-attribute Decision Making: A Simulation Comparison of Selected Methods." European Journal of Operational Research 107: 507-529.

Zoffer, J., A. Bahurmoz, M. K. Hamid, M. Minutolo, and T. L. Saaty. 2008. "Synthesis of Complex Criteria Decision Making: A Case Towards a Consensus Agreement for a Middle East Conflict Resolution." Group Decision Negotiation 17: 363-385. 


\section{Annex I (For the expansions of abbreviations please refer to Table 2.)}

Urban and social system subnetwork: the unweighted supermatrix.

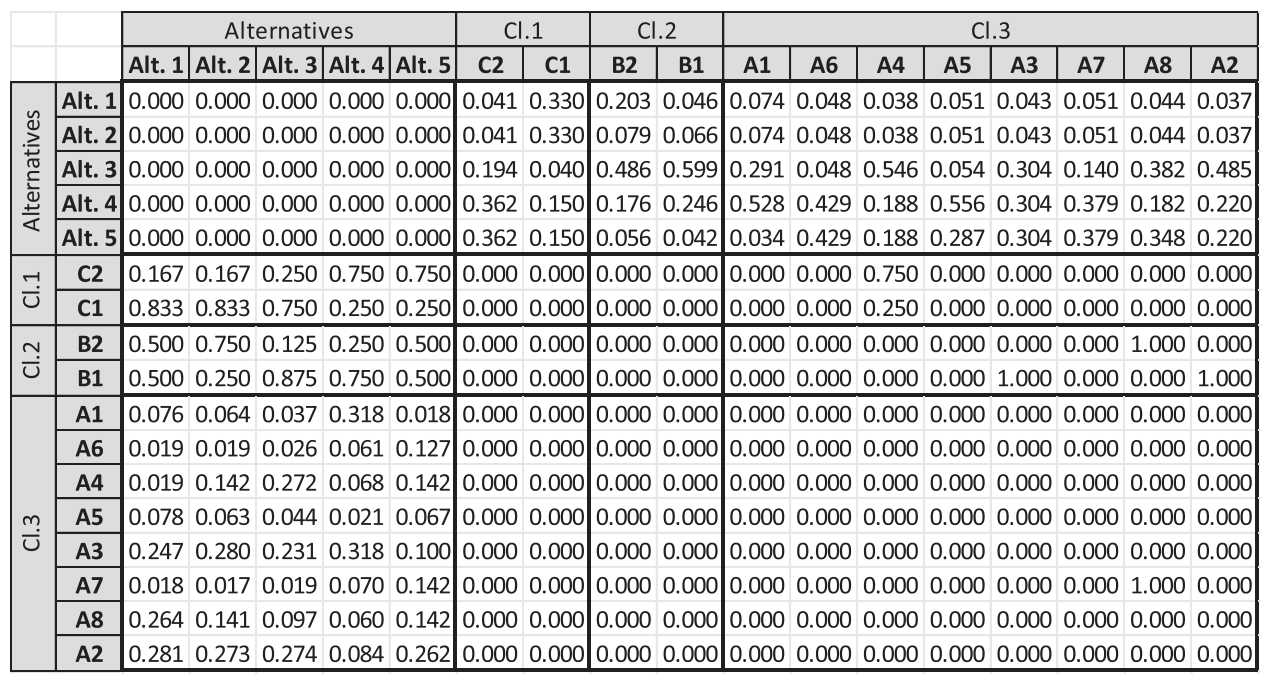

Cl.1, promotion and valorization of cultural events; Cl.2, requalification of downgraded urban areas; Cl.3, city valorization and requalification.

Urban and social system subnetwork: the weighted supermatrix.

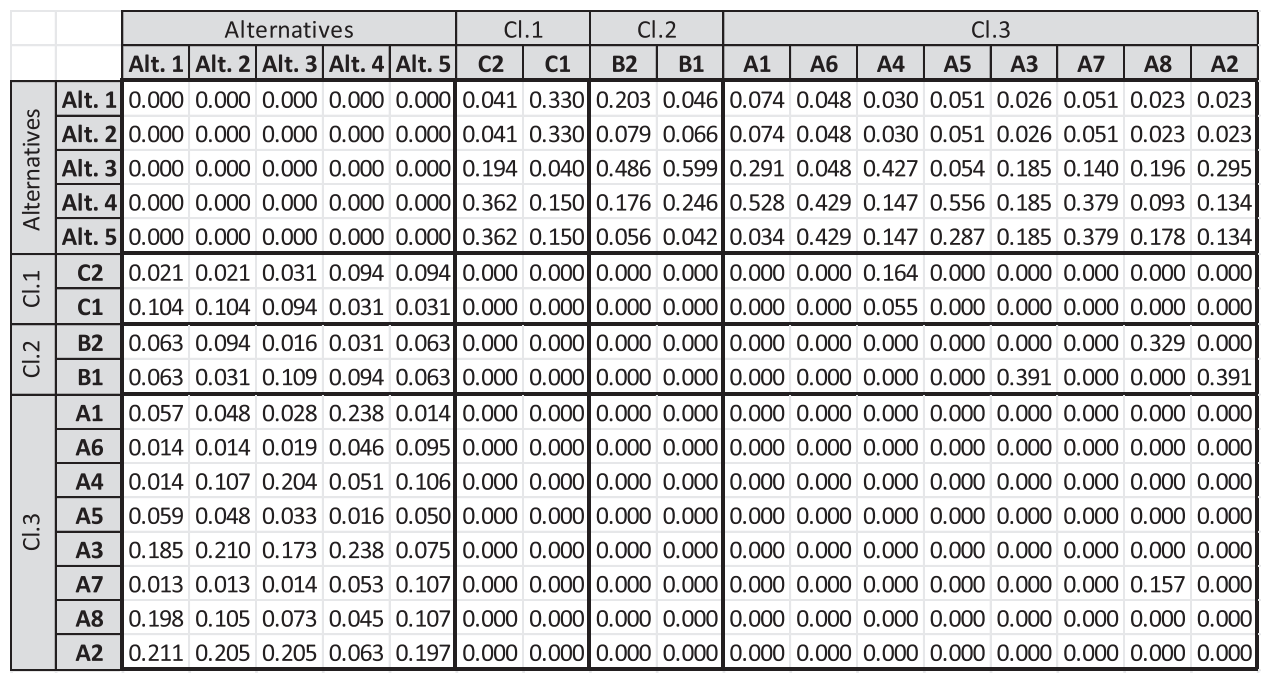

Cl.1, promotion and valorization of cultural events; Cl.2, requalification of downgraded urban areas; Cl.3, city valorization and requalification. 
Natural and cultural system subnetwork: the unweighted supermatrix.

\begin{tabular}{|c|c|c|c|c|c|c|c|c|c|c|c|c|c|c|c|c|c|c|c|c|c|}
\hline & & \multicolumn{5}{|c|}{ Alternatives } & Cl.1 & \multicolumn{8}{|c|}{$\mathrm{Cl} .2$} & \multicolumn{3}{|c|}{$\mathrm{Cl} .3$} & \multicolumn{3}{|c|}{ Cl. 4} \\
\hline & & t. 1 & Alt. 2 & Alt. 3 & Alt. 4 & Alt. 5 & G1 & D5 & D8 & D7 & D4 & D1 & D3 & D6 & 22 & E1 & E3 & E2 & F3 & F1 & F2 \\
\hline \multirow{5}{*}{ 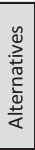 } & Alt. 1 & 0.000 & 0.000 & 0.000 & 0.000 & 0.000 & 0.110 & 0.193 & 0.237 & 0.157 & 0.128 & 0.157 & 0.129 & 0.141 & 0.123 & 0.483 & 0.201 & 0.228 & 0.432 & 0.451 & 0.455 \\
\hline & Alt. 2 & 0.000 & 0.000 & 0.000 & 0.000 & 0.000 & 110 & 193 & 0.143 & 0.157 & 0.200 & 0.157 & 0.133 & 0.421 & 0.257 & 0.270 & 0.086 & 0.151 & 0.273 & 0.156 & 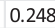 \\
\hline & IIt. 3 & 0.000 & 00 & 000 & 0.000 & 0.000 & 417 & 0.459 & 0.058 & 550 & 41 & 0.550 & 0.053 & 294 & .507 & 0.060 & 43 & 0.056 & 0.067 & 0.156 & the \\
\hline & It. 4 & 0.000 & c & 000 & 0.000 & 0.000 & 139 & 095 & 0.270 & 85 & 082 & 0.085 & 0.193 & 090 & .069 & 0.128 & 0.201 & 500 & 0.126 & 156 & ( \\
\hline & Alt. 5 & 0.000 & 0.000 & 0.000 & 0.000 & 0.000 & 0.224 & 0.060 & 0.292 & 0.050 & 0.048 & 0.050 & 0.493 & 0.054 & 0.044 & 0.060 & 0.469 & 0.065 & 0.101 & 0.081 & 0.0 \\
\hline & G1 & 000 & 1 & 1.000 & 1.000 & 1.000 & 0.000 & 0.000 & 0.000 & 0.000 & 0.000 & 0.000 & 0.00 & 0.000 & 0.000 & 0.000 & 0.00 & 0.000 & 0.000 & 0.00 & 0.000 \\
\hline \multirow{8}{*}{$\bar{U}$} & D5 & 229 & 0.365 & 0.062 & 0.036 & 0.174 & 0.000 & 0.000 & 0.000 & 000 & 000 & 1.000 & 0.000 & 0.000 & 1.000 & 0.000 & 0.000 & 0.00 & 0.000 & 0 & 0.00 \\
\hline & D8 & 438 & 30 & 563 & 0.515 & 0.068 & 0.000 & 000 & 0. & 0 & 10 & 0. & 0 & c & 0 & 0 & & ( & 0 & & ( \\
\hline & D7 & 038 & 30 & 3 & 0 & 428 & 0.000 & 000 & 0 & 0 & 0 & 0 & 0 & 0 & 000 & 00 & 0 & 000 & 0 & ) & 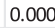 \\
\hline & D4 & 0.150 & 0.061 & 063 & 0.036 & 0.032 & 0.000 & 0.000 & 0.000 & 0.000 & 00 & 0.000 & 0.000 & 0.000 & 0.000 & 0.000 & 0.000 & 0.000 & 0.000 & 000 & 0.000 \\
\hline & D1 & 0.038 & 0.043 & 0.063 & 0.270 & 0.049 & 0.000 & 0.000 & 0.000 & 0.000 & 0.000 & 0.000 & 0.000 & 0.000 & 0.000 & 0.000 & 0.000 & 0.000 & 0.000 & 00 & 0.000 \\
\hline & D3 & 038 & 0.043 & 0.063 & 0.036 & 0.033 & 0.000 & 0.000 & 0.000 & 0.000 & 0.000 & 0.000 & 0.000 & 0.000 & 0.000 & 0.000 & 0 & 0.00 & 0.000 & 0 & $0 . c$ \\
\hline & D6 & 034 & 0 & 0.063 & 0.036 & 0.161 & 0.000 & 0.000 & 0.000 & 0.000 & 00 & 0.000 & 0.000 & 0.000 & 0.000 & 0.000 & 0 & 0.00 & 0.000 & 0 & 0.0 \\
\hline & D2 & 0.034 & 0.215 & 0.063 & 0.036 & 0.055 & 0.000 & 0.000 & 0.000 & 0.000 & 0.000 & 0.000 & 0.000 & 0.000 & 0.000 & 0.000 & 0.000 & 0.000 & 0.000 & 0.000 & 0.000 \\
\hline \multirow{3}{*}{$\stackrel{m}{u}$} & E1 & 0.793 & 0.793 & 0.053 & 0.194 & 0.183 & 0.000 & 0.000 & 0.000 & 0.000 & 0.000 & 0.000 & 0.000 & 0.000 & 0.000 & 0.000 & 0 & 0.000 & 0.000 & Do & 0.000 \\
\hline & E3 & 076 & 0.076 & 0.474 & 0.063 & 0.075 & 0.000 & 0.000 & 0.000 & 0.000 & 00 & 0.000 & 0.000 & Do & 0.000 & 0.000 & & 0.000 & 0.000 & & 0 \\
\hline & E2 & 0.131 & 0.131 & 0.474 & 0.743 & 0.742 & 0.000 & 0.000 & 0.000 & 0.000 & 0.000 & 0.000 & 0.000 & 0.000 & 0.000 & 0.000 & 0.000 & 0.000 & 0.000 & 0.000 & 0.000 \\
\hline \multirow{3}{*}{$\stackrel{+}{\dot{U}}$} & F3 & 0.057 & 0.278 & 0.818 & 0.429 & 0.429 & 0.000 & 0.000 & 0.000 & 0.000 & 0.000 & 0.000 & 0.000 & 0.000 & 0.000 & 0.000 & 0.000 & 0.000 & 0.000 & 0.000 & 0.000 \\
\hline & F1 & 0.597 & $0 . c$ & 0.091 & 0.429 & 0.429 & 0.000 & 0.000 & 0.000 & 0.000 & & & & 0.000 & 0.000 & 0.000 & & 0.000 & 0.000 & 00 & 0.000 \\
\hline & . & & & & & 107 & & & & & & & & & 0.000 & | 10.000 & 0.000 & 0.000 & 0.000 & 1.000 & 0 \\
\hline
\end{tabular}

Cl.1, soil consumption reduction; Cl.2, optimization of the use of environmental resources; Cl.3, protection and valorization of the cultural heritage; Cl.4, conservation and valorization of the natural heritage.

Natural and cultural system subnetwork: the weighted supermatrix.

\begin{tabular}{|c|c|c|c|c|c|c|c|c|c|c|c|c|c|c|c|c|c|c|c|c|c|}
\hline & & \multicolumn{5}{|c|}{ Alternatives } & 1 & \multicolumn{8}{|c|}{$\mathrm{Cl} .2$} & \multicolumn{3}{|c|}{$\mathrm{Cl} .3$} & \multicolumn{3}{|c|}{$\mathrm{Cl} .4$} \\
\hline & & 1 & 2 & Alt. 3 & Alt. 4 & Alt. 5 & 1 & D5 & D8 & D7 & 4 & D1 & D3 & 6 & D2 & E1 & E3 & E2 & $\mathrm{F3}$ & F1 & $F 2$ \\
\hline \multirow{5}{*}{$\frac{\bar{\Phi}}{\frac{ \pm}{\alpha}}$} & 1 & 00 & 0 & 0 & 0 & 0.000 & 10 & 0.193 & 0.237 & 0.131 & 0.128 & 0.131 & 0.129 & 0.141 & 0.102 & 0.362 & 0.201 & 0.228 & 0.432 & 0.301 & 455 \\
\hline & 2 & 00 & 0 & 0.000 & 0.000 & 0.000 & & 93 & 0.143 & 0.131 & 0.200 & 0.131 & 0.133 & 0.421 & 0.214 & 0.202 & 0.086 & 0.151 & 0.273 & 04 & 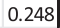 \\
\hline & Alt. 3 & 0 & 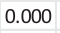 & & 00 & 0.000 & & 59 & 0.058 & 458 & 0.541 & 0.458 & 0.053 & 0.294 & 0.42 & 045 & 0.043 & 0.056 & 067 & 04 & 0 \\
\hline & t. 4 & & & & & 0.000 & & & 70 & 71 & 0.0 & 71 & 93 & 0.090 & 0.058 & 0.096 & 201 & 0.500 & 126 & 104 & 150 \\
\hline & Alt. 5 & 00 & 0.000 & 0.000 & 0.000 & 0.000 & 24 & 0.060 & 0.292 & 041 & 0.048 & 0.041 & 0.493 & 0.054 & 0.037 & 0.045 & 0.469 & 0.065 & 0.101 & 0.054 & 0.070 \\
\hline$\stackrel{-1}{U}$ & 1 & 54 & 54 & 0.354 & 0 & 354 & 00 & 0.000 & 00 & .000 & 0.000 & 0.000 & ( & 000 & 000 & 000 & 0.000 & 00 & 000 & 0.00 & 0.000 \\
\hline \multirow{8}{*}{$\stackrel{N}{\mathcal{U}}$} & D5 & 81 & 9 & 2 & 0.013 & 0.062 & 000 & 0.000 & 000 & 7 & 0.000 & & 0.000 & 0 & 0.167 & 000 & 0 & 0.000 & 000 & & 1.0 \\
\hline & D8 & 5 & 0.013 & 0. & 0.182 & 0.024 & 000 & 0.000 & 0.000 & 0.000 & 0.000 & 0 & 0.000 & 0.000 & 0.000 & 0.000 & 0 & 0.000 & 000 & & 0.0 \\
\hline & D7 & 4 & 3 & 0. & 3 & 0.151 & 500 & 0.000 & 0.0 & 0 & 0.0 & 0. & 0.000 & 0. & 0.000 & 0.000 & 0 & 0.000 & 0 & & 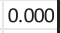 \\
\hline & D4 & 053 & 22 & 0.022 & 0.013 & 0.011 & 000 & 0.000 & 00 & 00 & 0.000 & 00 & 000 & 00 & 0.000 & 0.000 & 000 & 0.000 & 0.000 & v & 000 \\
\hline & D1 & 014 & 15 & 0.022 & 0.096 & 0.017 & .000 & 0.000 & 0.000 & 0.000 & 0.000 & 0. & 0.000 & 0 & 0.000 & 0.000 & 0 & 0.000 & 0.000 & & 0.000 \\
\hline & D3 & 14 & 5 & 0.022 & 0.013 & 0.012 & .000 & 0.000 & 0.000 & 0.0 & 0.0 & & 0.000 & & 0.000 & 0. & 0 & 0.000 & 00 & & 0.0 \\
\hline & D6 & 12 & 076 & 0. & 0.013 & 0.057 & 000 & 0.000 & 0.000 & 0.000 & 0.0 & & 0 & $0 . C$ & 0.000 & 0.000 & 0 & 0.000 & 0.000 & & 0.00 \\
\hline & D2 & 12 & 0.076 & 0.022 & 0.013 & 0.019 & 000 & 0.000 & 000 & 0.000 & 0.000 & 0.000 & 000 & Do & 0.000 & 0.000 & 0.000 & 0.000 & 0.000 & c & .000 \\
\hline \multirow{3}{*}{ ü } & E1 & .04 & 14 & 7 & 0.025 & 0.024 & 0.000 & 0.000 & 0.000 & 0.0 & 0.000 & 0. & 0.000 & & 0.000 & 0.000 & 0 & 0.000 & 0 & & 0.000 \\
\hline & E3 & 10 & 0. & $0 . C$ & 0.008 & 0.010 & 0.000 & 0.000 & 0 & 0. & 0.0 & & 0 & 0. & 0.000 & 0.000 & 0.000 & 0.000 & 0.000 & & 0.000 \\
\hline & E2 & 17 & 0.017 & 0.062 & 0.098 & 0.097 & 0.000 & 0.000 & 0.000 & 0.000 & 0.000 & 0.000 & 0.000 & 0.000 & 0.000 & 0.000 & 0.000 & 0.000 & 0.000 & 0.000 & 0.000 \\
\hline \multirow{3}{*}{-} & F3 & 009 & 0.045 & 0.131 & 0.069 & 0.069 & 0.000 & 0.000 & 0.000 & 0.000 & 0.000 & 0.000 & 0.000 & 0.000 & 0.000 & 0.000 & 0.000 & 0.000 & 0.000 & 0.000 & 0.000 \\
\hline & F1 & 0.096 & 0.009 & 0.015 & 0.069 & 0.069 & 0.000 & 0.000 & 0.000 & 0.000 & 0.0 & & 0.000 & 0. & 0.000 & 0.000 & 0.000 & 0.000 & 0.000 & 0.00 & 0.000 \\
\hline & F2 & 0.056 & 0.107 & 0.015 & 0.023 & 0.023 & 0.000 & 0.000 & 0.000 & 0.000 & 0.000 & 0.000 & 0.000 & 0.000 & 0.000 & 0.250 & 0.000 & 0.000 & 0.000 & 0.333 & 0.000 \\
\hline
\end{tabular}

Cl.1, soil consumption reduction; Cl.2, optimization of the use of environmental resources; Cl.3, protection and valorization of the cultural heritage; Cl.4, conservation and valorization of the natural heritage. 
Economic and mobility system subnetwork: the unweighted supermatrix.

\begin{tabular}{|c|c|c|c|c|c|c|c|c|c|c|c|c|c|}
\hline & & \multicolumn{5}{|c|}{ Alternatives } & $\mathrm{Cl} .1$ & \multicolumn{4}{|c|}{$\mathrm{Cl} .2$} & \multicolumn{2}{|c|}{$\mathrm{Cl} .3$} \\
\hline & & t. 1 & Alt. 2 & Alt. 3 & Alt. 4 & Alt. 5 & I1 & $\mathrm{H} 2$ & H3 & H4 & $n \perp$ & L1 & L2 \\
\hline \multirow{5}{*}{ 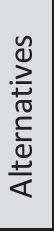 } & & 00 & 0 & 0 & c & 00 & 118 & 0.337 & 24 & 48 & 51 & 21 & c \\
\hline & Alt. 2 & 0.000 & 0.000 & 0.000 & 0 & 0.000 & 0.048 & 37 & & 0.048 & 0.037 & 0.421 & דלנ. \\
\hline & It. 3 & 0.000 & 0.000 & 0.000 & 0.000 & 0.000 & 0.032 & 0.025 & 0.031 & 0.048 & 0.028 & 0.043 & 0.033 \\
\hline & Alt. 4 & 0.000 & 0.000 & 0.000 & 0.000 & 0.000 & 0.292 & 0.117 & 0.279 & 0.429 & 0.392 & 0.043 & 0.033 \\
\hline & t. 5 & 0 & 0 & 0 & c & 0 & 0 & 4 & 0 & 9 & 2 & 2 & $\underline{0}$ \\
\hline$\frac{r}{U}$ & & & & & & & 0 & & & & & & $\mathrm{C}$ \\
\hline \multirow{4}{*}{$\frac{N}{U}$} & & & & & & & & & & & & & \\
\hline & H3 & 3 & 0 & 0 & & 6 & 0.000 & 0 & & & 00 & 00 & 0 \\
\hline & H4 & 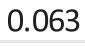 & & & & & 0.000 & & & & 0.000 & 0.000 & 0.00 \\
\hline & $\mathrm{Ma}$ & 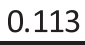 & 0.442 & 0.250 & 0.521 & 0.211 & 0.000 & 0.000 & 0.000 & 0.000 & 0.000 & 0.000 & 0.000 \\
\hline \multirow{2}{*}{$\frac{m}{\dot{u}}$} & & & & 0.500 & & 0.100 & 0.000 & 0.000 & 0.0 & 0.000 & 0.000 & 00 & 0.000 \\
\hline & 2 & 25 & 0.125 & 0.500 & 0.500 & 900 & 000 & 0.000 & 0.000 & 0.000 & 0.000 & 0.000 & מחת ח \\
\hline
\end{tabular}

Cl.1, promotion of economic activities connected to the tourist sector; Cl.2, rationalization of the transport system inside the tourist territory; $\mathrm{Cl} .3$, enhancement of agricultural areas as sustainable productive areas.

Economic and mobility system subnetwork: the weighted supermatrix.

\begin{tabular}{|c|c|c|c|c|c|c|c|c|c|c|c|c|c|}
\hline & & \multicolumn{5}{|c|}{ Alternatives } & $\mathrm{Cl} .1$ & \multicolumn{4}{|c|}{$\mathrm{Cl} .2$} & \multicolumn{2}{|c|}{$\mathrm{Cl} .3$} \\
\hline & & Alt. 1 & Alt. 2 & Alt. 3 & Alt. 4 & Alt. 5 & 11 & $\mathrm{H} 2$ & H3 & H4 & $\mathrm{H} 1$ & L1 & $\mathbf{L} 2$ \\
\hline \multirow{5}{*}{ 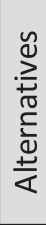 } & Alt. 1 & 0.000 & 0.000 & 0.000 & 0.000 & 0.000 & 0.118 & 0.225 & 0.124 & 0.048 & 0.151 & 0.421 & 0.177 \\
\hline & Alt. 2 & 0.000 & 0.000 & 0.000 & 0.000 & 0.000 & 0.048 & 0.225 & 0.124 & 0.048 & 0.037 & 0.421 & 0.194 \\
\hline & Alt. 3 & 0.000 & 0.000 & 0.000 & 0.000 & 0.000 & 0.032 & 0.017 & 0.031 & 0.048 & 0.028 & 0.043 & 0.033 \\
\hline & Alt. 4 & 0.000 & 0.000 & 0.000 & 0.000 & 0.000 & 0.292 & 0.078 & 0.279 & 0.429 & 0.392 & 0.043 & 0.033 \\
\hline & Alt. 5 & 0.000 & 0.000 & 0.000 & 0.000 & 0.000 & 0.510 & 0.123 & 0.443 & 0.429 & 0.392 & 0.072 & 0.563 \\
\hline$\stackrel{r}{U}$ & I1 & 0.130 & 0.130 & 0.130 & 0.130 & 0.130 & 0.000 & 0.333 & 0.000 & 0.000 & 0.000 & 0.000 & 0.000 \\
\hline \multirow{4}{*}{$\frac{N}{U}$} & $\mathrm{H} 2$ & 0.521 & 0.324 & 0.183 & 0.025 & 0.028 & 0.000 & 0.000 & 0.000 & 0.000 & 0.000 & 0.000 & 0.000 \\
\hline & H3 & 0.083 & 0.052 & 0.183 & 0.163 & 0.275 & 0.000 & 0.000 & 0.000 & 0.000 & 0.000 & 0.000 & 0.000 \\
\hline & $\mathrm{H} 4$ & 0.046 & 0.032 & 0.183 & 0.163 & 0.275 & 0.000 & 0.000 & 0.000 & 0.000 & 0.000 & 0.000 & 0.000 \\
\hline & H1 & 0.083 & 0.324 & 0.183 & 0.381 & 0.155 & 0.000 & 0.000 & 0.000 & 0.000 & 0.000 & 0.000 & 0.000 \\
\hline \multirow{2}{*}{$\frac{m}{u}$} & L1 & 0.121 & 0.121 & 0.069 & 0.069 & 0.014 & 0.000 & 0.000 & 0.000 & 0.000 & 0.000 & 0.000 & 0.000 \\
\hline & L2 & 0.017 & 0.017 & 0.069 & 0.069 & 0.124 & 0.000 & 0.000 & 0.000 & 0.000 & 0.000 & 0.000 & 0.000 \\
\hline
\end{tabular}

Cl.1, promotion of economic activities connected to the tourist sector; Cl.2, rationalization of the transport system inside the tourist territory; Cl.3, enhancement of agricultural areas as sustainable productive areas. 